\title{
Hepatitis crónica por virus C. Datos epidemiológicos y de eficacia terapéutica en 255 casos
}

\author{
A. PÉREZ MOTA, M. A. BLANCO CORONADO, J. GRAUS MORALES, \\ R. RODERO VÁZQUEZ DE CASTRO, C. PÉREZ MUÑOZ, J. L. DE VICENTE \\ BACH, C. VILLALGORDO APARICIO
}

Servicio de Aparato Digestivo. Hospital Virgen de la Torre y Área Sanitaria 1. Madrid

\author{
CHRONIC HEPATITIS C. EPIDEMIOLOGY AND THERAPEUTIC \\ RESULTS IN 255 CASES
}

\section{RESUMEN}

Revisando la estadística de los años 2003, 2004, hasta agosto de 2005 , tenemos datos correspondientes a 255 pacientes que fueron diagnosticados e introducidos en protocolo de tratamiento de hepatitis crónica por virus $\mathrm{C}$.

Epidemiológicamente es de destacar la proporción de 2/1 entre hombre/mujer, edad media de 43 años y antecedentes de transfusión (Transf.) en un $18,6 \%$. Adicción a drogas por vía parenteral (ADVP) en el $17 \%$ y etilismo del $14,1 \%$, siendo el origen desconocido en el $58,74 \%$ de los casos.

Correspondieron al genotipo 1 el 79,05\% de los casos, genotipo 4 el $4,74 \%$, genotipo 3 el $14,22 \%$ y genotipo 2 el $2,76 \%$. Los genotipos 1 y 4 fueron introducidos en protocolo de tratamiento con PEG-interferón alfa$2 \mathrm{~b}+$ ribavirina (con dosis ajustadas según peso) y los de genotipo 3 y 2 con interferon alfa $2 \mathrm{~b}+$ ribavirina.

En los 95 casos de genotipo 1 (87) y 4 (8), se obtuvo una respuesta viral sostenida (RVS) del 61,95\%, con tres abandonos.

De los 20 casos de genotipos 3 (17) y 2 (3), la RVS fue del $85 \%$, sin ningún abandono

El ajuste del tratamiento al peso supuso un ahorro económico por caso, teniendo sólo en cuenta PEG-interferón, que se cifró en 868,94 €.

Por último, grupo de 16 casos del genotipo 1 había sido tratado anteriormente con interferón en monoterapia, consiguiéndose con el nuevo tratamiento una RVS en 5 casos de los primeros $(31,25 \%)$.

PALABRAS CLAVE: Tratamiento PEG-interferón más ribavirina en HCVC. Hepatitis crónica por virus C.

\begin{abstract}
A review of the statistics of the years 2003, 2004 to August 2005 has provided data corresponding to 255 patients that were diagnosed and included in the treatment protocol of chronic hepatitis $C$.

Epidemiologically, the $2 / 1 \mathrm{man} /$ woman ratio, mean age of 43 years and history of transfusion (transf.) in $18.6 \%$ are to be noted. Parenteral drug addcition (PDA) in $17 \%$ and alcoholism in $14.1 \%$, of unknown origin in $58.74 \%$ of the cases.

$79.05 \%$ corresponded to genotype 1, $4.74 \%$ to genotype 4, $14.22 \%$ to genotype 3 , and $2.76 \%$ to genotype 2. Genotypes 1 and 4 were includ$e d$ in the treatment regime with PEG-Interferon alpha- $2 b+$ Ribavirin (with doses adjusted for weight) and those of genotype 3 and 2 in the regime with Interferon alpha $2 b+$ Ribavirin.

In 95 cases of Genotype 1 (87) and 4 (8), a sustained viral response (SVR) of 61.95\% was obtained, with three drop-outs. In the 20 cases of genotypes 3 (17) and 2 (3), SVR was $85 \%$, with no drop-outs. In the 20 cases of genotypes 3 (17) and 2 (3), SVR was $85 \%$, with no drop-outs.

The adjustment of treatment to body mass involved an economic savings per case amounting to $868.94 €$.

Finally, in 16 cases of Genotype 1, before treated with Interferon in monotherapy, a sustained viral response of $31.25 \%$ was obtained with combined therapy.
\end{abstract}

KEY WORDS: Chronic $C$ hepatitis. Treatment of chronic hepatitis $C$ with PEG-interferon alfa $2 b+$ ribavirin.

Pérez Mota A, Blanco Coronado M ${ }^{a}$ A, Graus Morales J, Rodero Vázquez de Castro R, Pérez Muñoz C, de Vicente Bach JL, Villalgordo Aparicio C. Hepatitis crónica por virus C. Datos epidemiológicos y de eficacia terapéutica en 255 casos. An Med Interna (Madrid) 2006; 23: 257-259.

\section{INTRODUCCIÓN}

La hepatitis crónica por virus $\mathrm{C}$, constituye en la actualidad la hepatopatía viral mas prevalente y la causa mas habitual de la evolución a una cirrosis y la aparición de un hepatocarcinoma (1). De aquí la necesidad de llevar a cabo su diagnóstico para someter al paciente a tratamientos, que de forma progresiva han ido mejorando en eficacia y en confortabilidad (2).

En España se calcula que alrededor de 800.000 personas presentan una infección crónica por virus $\mathrm{C}$, siendo el genotipo mas prevalente el de tipo 1 (alrededor del 80\%), que pre-

Trabajo aceptado: 4 de enero de 2006 
senta una menor sensibilidad frente a los tratamientos combinados actuales, frente a los genotipos 2 y 3 (sobre un 15\%) con una mayor eficacia terapéutica $(1,2,4)$.

\section{MATERIAL Y MÉTODO}

A partir del 1 de enero de 2003 y hasta el 1 de agosto de 2005, hemos introducido 255 pacientes, con el diagnóstico de hepatitis crónica por virus $\mathrm{C}$, para tratamiento de la misma.

El diagnóstico de todos ellos estaba basado en la elevación persistente de aminotransferasas, VHC-RNA positivo, con genotipo y carga viral, y biopsia hepática con características histológicas de hepatitis crónica.

De acuerdo con el genotipo se introdujeron los pacientes en dos pautas diferentes de tratamiento:

-Genotipo 1 y 4: PEG-interferón alfa $2 \mathrm{~b}+$ ribavirina, con dosis ajustadas según peso (PEG-INF: $1,5 \mathrm{microg} / \mathrm{kg}$ y Ribavirina (800 mg < 65 kg; $1.000 \mathrm{mg}$ de $65-85$ y $1.200 \mathrm{mg}$ $>85 \mathrm{~kg}$ )

Comenzando con intención de tratar durante 48 semanas, pero recomendando realizar carga viral a las 12 semanas, para comprobar su eficacia predictiva en el resultado final.

-Genotipos 2 y 3: interferon alfa 2b, con $3 \mathrm{MU} / 3$ veces semana y ribavirina según peso con la pauta antedicha.

Comenzando con intención de tratar de 24 semanas.

A partir del 1 de enero de 2005 se unificó el tratamiento con PEG-INF en todos los genotipos, aunque conservando la intención de tratar de 24 semanas en los genotipos 2 y 3 .

Todos los pacientes fueron revisados mensualmente, bajo el punto de vista clínico y analítico, realizando una nueva carga viral a los seis meses de terminar el tratamiento para valorar la respuesta.

\section{RESULTADOS}

\section{EPIDEMIOLÓGICOS}

Bajo el punto de vista epidemiológico, los 255 pacientes correspondieron a los diferentes genotipos en la siguiente proporción:

\begin{tabular}{|c|c|}
\hline po 1 & $5 \%$ \\
\hline$-C$ & ( \\
\hline$-\mathrm{G}$ & $2 \%$ \\
\hline$-\mathrm{G}$ & $.2,76 \%$ \\
\hline
\end{tabular}

En los 255 pacientes la relación hombre/mujer fue de 2/1, con una edad media de 43,03 años y peso medio de $74,45 \mathrm{~kg}$.

En cuanto a posibles antecedentes causales de su hepatitis crónica por virus $\mathrm{C}$, en la mayor parte eran desconocidos $(58,74 \%)$, seguidos de transfusión $(18,6 \%)$, adicción a drogas por vía parenteral (ADVP) en el $17 \%$ del conjunto de todos los pacientes, llegando al $55 \%$ entre los de genotipos 2 y 3 . Por último el etilismo figuraba como antecedente en el $14,1 \%$.

En los datos analíticos previos al tratamiento destaca la carga viral media que fue de $1.850 .469 \mathrm{UI} / \mathrm{ml}$ (de $1.120 \mathrm{a}$ 53.000.000) siendo las aminotransferasas con medias de AST: 61,11 UI/ml y ALT: 101,38 UI/ml.

\section{EFICACIA TERAPÉUTICA}

De los genotipos 1 y 4 podemos evaluar un total de 95 pacientes, 87 casos del genotipo 1 y 8 del 4 .

De los 95 pacientes concluyeron el tratamiento de 48 semanas 92, contando con 3 abandonos, todos del genotipo 1, dos por decisión médica, basada en uno en fenómenos alérgicos importantes y en otro en notable adelgazamiento, y otro por decisión del paciente ante los efectos secundarios habituales (cuadro gripal).

Además de los abandonos señalados hubo 5 casos de efectos secundarios llamativos, también del genotipo 1, aunque no motivaron interrupción del tratamiento. Así dos casos de depresión y 3 de anemia hemolítica que obligaron a reducir la dosis de ribavirina y, entre ellos uno de hemólisis rápida que preciso transfusión urgente.

La respuesta viral sostenida (RVS) de este grupo de 92 fue de 57 pacientes $(61,95 \%)$ y la respuesta viral negativa fue de 35 pacientes $(38,04 \%)$.

El genotipo 4, formado por 8 pacientes tuvo una RVS algo inferior (4 casos, $50 \%$ ) aunque el pequeño número no permite sacar conclusiones.

De los 92 pacientes, 20 (21,7\%), todos del genotipo 1, habían sido sometidos anteriormente a tratamientos antivirales. Dieciséis con interferón en monoterapia y cuatro con la combinación de interferón mas ribavirina. Entre los de monoterapia con INF, se obtuvo RVS en 5 de ellos (31,25\%), mientras que no se consiguió ninguna RVS en los 4 con antecedente de terapia combinada.

Entre los 35 casos de RVN se había demostrado una carga viral superior a $30.000 \mathrm{UI} / \mathrm{ml}$ a las 12 semanas en 31 casos, lo que da una seguridad del $88,5 \%$ en la falta de respuesta a las 48 semanas, aunque una pequeña proporción de 3 casos $(14,2 \%)$ obtuvieron a las 48 semanas RVS, pudiendo tratarse de los llamados respondedores lentos.

El grupo de genotipos 2 y 3 estuvo formado por 20 pacientes (17 del genotipo 3 y tres del genotipo 2 ), con una RVS en 17 pacientes $(85 \%)$, que fue del $100 \%$ entre los tres casos de genotipo 2.

Para el cálculo del coste económico, se analizaron únicamente los 48 casos valorados en el transcurso del año 2005, con el fin de tener un único precio de referencia. El peso medio fue de $71 \mathrm{~kg}$ y el $95 \%$ pertenecían a los genotipos 1 y 4 , siendo el otro $5 \%$ de los genotipos 2 y 3 , con un tiempo medio de tratamiento de 38,8 semanas. El ahorro económico ajustando los microgramos de PEG-interferón al peso del paciente se cifró en un 13,2\% (41.700,22 €) en nuestros 48 casos, equivalente por caso a $868,94 €$, con precios de referencia y descuentos iguales y correspondientes al año 2005. Faltaría valorar otros aspectos clínicos derivados de la "sobredosificación" al utilizar una dosis estándar de PEG-interferón por paciente.

\section{DISCUSIÓN}

El diagnóstico de nuestros pacientes se ajustó a las premisas habituales, aunque en la actualidad se cuestiona la necesidad de la biopsia hepática, ya que en la mayor parte de los casos los datos obtenidos de la misma no van a influir en la decisión terapéutica (3).

Los datos epidemiológicos de nuestra serie son similares a los publicados en otras ocasiones (4), llamando la atención un 
relativo mayor número de casos de genotipo 4 (5). En cuanto al resto de parámetros etiológicos, de edad, sexo, etc. son similares a los descritos habitualmente en la literatura (6).

Los resultados terapéuticos señalan también la tendencia habitual de menor respuesta del genotipo $1 \mathrm{y}$, aunque con poco número de casos, aún menor en el caso del genotipo 4 , como ya publicamos anteriormente $(5,7)$.

El retratamiento de pacientes tratados previamente con interferón en monoterapia ha mostrado también una respuesta aceptable del $31,25 \%$ teniendo en cuenta que todos pertenecían al genotipo 1 (8).

Es de señalar que ajustar las dosis terapéuticas al volumen corporal, o en su defecto al peso del paciente, como en nuestro caso, supone un ahorro económico no despreciable. También en este sentido debe tenerse en cuenta la respuesta a las 12 semanas, e incluso mas temprana (9), que resulta altamente predictiva y por tanto permite interrumpir el tratamiento en aquellos pacientes en que la carga viral persista por encima de 30.000 $\mathrm{UI} / \mathrm{ml}$ (10), con el subsiguiente ahorro económico, pero sobre todo, de efectos secundarios, en pacientes que no van a responder más que en pequeña proporción, debiéndose encontrar un marcador mas sensible para los llamados respondedores lentos.

\section{Bibliografía}

1. Rodríguez-Vidigal FF, Baz MJ, Romero J, Puerto M. Epidemiología del carcinoma hepatocelular en un área rural. Papel de los virus hepatotropos en la supervivencia. An Med Interna (Madrid) 2005; 22: 162-6.

2. Pérez A, Graus J, Blanco MA, Rodero R, Pérez C, Fernández J, et al. Resultados del tratamiento combinado, interferón más ribavirina, en la hepatitis crónica por virus C. Rev Esp Enferm Dig 2002; 94 (Supl. 1): 74-94.

3. Jensen DM. Liver biopsy in the management of hepatitis C: not always required. AGA Perspectives 2005; 1; 4: 5-12.

4. Pérez Mota A, Hepatitis crónica por virus C. Salud Rural 2001; 17: 19-36.

5. Pérez Mota A, Graus J, Blanco MA, Pérez Muñoz C, Villalgordo C, Rodero R. El genotipo 4 del virus $\mathrm{C}$ presenta una respuesta similar al genotipo 1 en el tratamiento combinado interferón + ribavirina de la hepatitis crónica. Rev Esp Enferm Dig 2003; 95: 238.

6. Alter MJ. The epidemiology of acute and chronic hepatitis C. Clin Liver
Por último señalar que en la actualidad, desde el 1 de enero de 2005 , tratamos a todos los pacientes de hepatitis C crónica, sin distinción de genotipo, en la combinación de ribavirina con interferón pegilado, dada su mayor comodidad de administración y posible mayor eficacia.

\section{AGRADECIMIENTO}

A los doctores Joaquín Fernández Velázquez, María Jesús García Sánchez y Gonzalo Guerra Flecha por su aportación de casos a la serie y a las Dras. Rocío Campos Cantero y Yolanda Real Martínez, por su colaboración en la práctica de endoscopias digestivas y control de las biopsias hepáticas. A doña $\mathrm{M}^{\mathrm{a}}$ Luz Sagrario y doña Emilia Martínez por su eficacia en la citación de los pacientes y su labor de secretaría.

Igualmente a la Dra. Concepción Esteban y a la DUE doña $\mathrm{M}^{\mathrm{a}}$ Jesús Zurimendi, del Servicio de Farmacia, que han iniciado y programado la entrega de medicación, sin ahorrar explicaciones a estos enfermos.
Dis 1997; 1: $559-568$.

7. Craxi A, Licata A. Clinical trial results of peginterferons in combination with ribavirin. Seminars in Liver Disease 2003; 23: 35-46.

8. Carnicer F, Zapater P, Gutiérrez A, García A, Ruiz F, López M. Tratamiento con PEG interferón alfa $2 \mathrm{~b}$ y ribavirina en enfermos previamente tratados con interferón estándar en monoterapia o combinado con ribavirina. Rev Esp Enferm Dig 2005; 97: 306-16.

9. Davis GL, Wong JB, McHutchison JG, Manns MP, Harvey J, Albrecht $\mathrm{J}$. Early virologic response to treatment with peginterferon alfa- $2 \mathrm{~b}$ plus Ribavirin in patientes with chronic hepatitis C. Hepatology 2003; 38 : 645-52.

10. Berg T, Sarrazin C, Herrmann E, Hinrichsen H, Gerlach T, Zachoval R, et al. Prediction of treatment outcome in patients with chronic hepatitis C: significance of baseline parameters and viral dinamics during therapy. Hepatology 2003; 37: 600-9. 